\title{
EFEKTIVITAS PELATIHAN ANALISIS SEDERHANA KESEHATAN TANAH SAWAH MELALUI METODE SEKOLAH LAPANG PETANI
}

\author{
M. Khais Prayoga ${ }^{1 *}$, Diyan Herdiantoro ${ }^{2}$, Roby I. Syarifain ${ }^{2}$, Mieke R. Setiawati ${ }^{2}$, Kustiwa \\ Adinata $^{3}$, Silke Stoeber ${ }^{4}$ dan Tualar Simarmata ${ }^{2}$ \\ ${ }^{1}$ Pusat Penelitian Teh dan Kina, Bandung, Indonesia \\ ${ }^{2}$ Fakultas Pertanian, Universitas Padjadjaran, Bandung, Indonesia \\ ${ }^{3}$ Jaringan Masyarakat Tani Indonesia, Pangandaran, Indonesia \\ ${ }^{4}$ Centre for Rural Development (SLE) Humboldt-Universität zu Berlin, Berlin, Germany \\ *mkprayoga@iritc.org
}

\begin{abstract}
Abstrak
Intrusi air laut dan meluapnya sungai akibat curah hujan yang tinggi karena dampak perubahan iklim menyebakan menurunya tingkat kesehatan tanah sawah. Petani perlu dilatih untuk menganalisis kesehatan tanah sawah secara sederhana melalui sekolah lapang. Pelatihan analisis sederhana kesehatan tanah sawah melalui metode sekolah lapang petani perlu diuji untuk mengetahui efektivitasnya dalam meningkatkan kemampuan petani. Penelitian dilaksanakan terhadap 17 petani yang berasal dari Desa Paledah dan Desa Ciganjeng (Kecamatan Padaherang, Kabupaten Pangandaran, Provinsi Jawa Barat) serta dari Desa Rawaapu dan Desa Cimurutu (Kecamatan Patimuan Kabupaten Cilacap, Provinsi Jawa Tengah). Alat ukur dalam penelitian ini adalah kuisioner pretest dan post test. Analisis yang digunakan adalah analisis statistik non parametrik ChiSquare. Besar kecilnya peningkatan keilmuan petani berdasarkan nilai pretest dan posttest dianalisis menggunakan uji $n$-gain. Hasil penelitian ini menunjukkan bahwa terdapat perbedaan yang nyata antara nilai rata-rata postest $(65,88)$ dengan nilai rata-rata pretest $(54,12)$ dan terjadi peningkatan sebanyak $21,74 \%$. Berdasarkan nilai gain faktor, peningkatan keilmuan petani tergolong sedang. Petani peserta pelatihan memberikan sikap yang positif terhadap kegiatan pelatihan dimana petani seluruhnya setuju dan sangat setuju bahwa materi sesuai dengan kebutuhan petani, pemateri menyampaikan materi dengan baik, materi yang diberikan mudah diterapkan, ketersediaan sarana dan prasarana sangat menunjang kegiatan, pelatihan berlangsung kondusif, pelatihan yang diberikan bermanfaat untuk petani, dan materi pelatihan akan coba diaplikasikan secara mandiri.
\end{abstract}

Kata kunci: perubahan iklim, kesehatan tanah, sekolah lapang petani

\section{Abstract}

Seawater intrusion and river overflows due to high rainfall due to the impact of climate change have decreased the health level of paddy fields. Farmers need to be trained to analyze the health of the paddy soil in a simple way through field schools. Simple analysis training of paddy soil health through farmer field school methods needs to be tested to determine its effectiveness in increasing farmers' abilities. The research was conducted on 17 farmers from Paledah Village and Ciganjeng Village (Padaherang District, Pangandaran Regency, West Java Province) as well as from Rawaapu Village and Cimurutu Village (Patimuan District, Cilacap Regency, Central Java Province). The measuring instrument in this study was a pretest and post test questionnaire. The analysis used is non-parametric statistical analysis Chi-Square. The size of the increase in farmer science based on the pretest and posttest values was analyzed using the n-gain test. The results of this study indicate that there is a significant difference between the average postest score (65.88) and the pretest average score (54.12) and there is an increase of $21.74 \%$. Based on the value of the gain factor, the increase in farmers' knowledge is moderate. The training participants gave a positive attitude towards training activities where all farmers agreed and strongly agreed that the material was in accordance with the farmers' needs, the presenters conveyed the material well, the material provided was easy to apply, the availability of facilities and infrastructure greatly supported the activity, the training was conducive, the training was good. provided benefits to farmers, and training materials will try to be applied independently.

Keyword: climate change, soil health, farmer field school

\section{Pendahuluan}

Tanah merupakan salah satu media tumbuh tanaman, baik tanaman semusim maupun tanaman tahunan untuk kemaslahatan manusia dan makhluk hidup lainnya. Tubuh tanah terdiri atas udara (20-30\%), air (20-30\%), bahan mineral (45\%), dan bahan organik (5\%) (Simarmata et al., 2018). Tanah bersifat sangat dinamis yaitu terus menerus mengalami perubahan yang dipengaruhi oleh bentuk wilayah (relief atau 
bentuk permukaan tanah), bahan induk, waktu, organisme dan iklim.

Perubahan iklim yang dirasakan saat ini memberikan dampak buruk terhadap kualitas tanah di wilayah pesisir selatan pulau Jawa. Intrusi air laut yang meningkat hingga $20 \mathrm{~km}$ dari garis pantai sebagai dampak dari perubahan iklim menjadi permasalahan serius bagi ekosistem pertanian khususnya areal pesawahan (Nafisah et al., 2017). Intrusi air laut membawa serta partikel-partikel garam dari laut dan mengakibatkan tingkat salinitas di lahan sawah menjadi tinggi (Rostini et al., 2020). Salinitas tanah yang tinggi menyebabkan kerusakan struktur tanah, menurunkan aerasi, permeabilitas, ketersediaan nitrogen, dan meningkatkan potensial osmotik tanah sehingga dapat mengganggu fisiologi tanaman (Kusrachdiyanti et al., 2020). Akumulasi $\mathrm{Na}^{+}$dan $\mathrm{Cl}^{-}$yang tinggi pada tanah juga menyebabkan penurunan hara tersedia seperti $\mathrm{K}^{+}$, $\mathrm{Ca}^{2+}, \mathrm{Fe}^{2+}$, dan $\mathrm{Mg}^{2+}$ dikarenakan kompetisi dengan $\mathrm{Na}^{+}$dan $\mathrm{Cl}^{-}$pada proses penyerapan hara oleh perakaran tanaman (Suprayogi \& Salsabila, 2019). Intrusi air laut bukan satu-satunya permasalahan yang terjadi akibat perubahan iklim di wilayah pesisir selatan pulau Jawa. Peningkatan intensitas curah hujan yang tinggi akibat perubahan iklim menyebabkan meluapnya sungai yang mengakibatkan banjir di areal pesawahan. Banjir yang terjadi dapat menurunkan tingkat kesehatan tanah sawah, karena terjadinya pencucian unsur hara tanah (Setiawati et al., 2020).

Kesehatan tanah merupakan hal yang penting dalam menunjang produktivitas tanaman seperti tanaman padi. Menurut Simarmata et al. (2018), kesehatan tanah merupakan keseimbangan ekologis dan fungsi dari tanah dalam menjaga produktivitas dan keseimbangan ekosistem dengan biodiversitas tinggi baik di atas tanah, maupun di dalam tanah. Karakter kimia, fisika dan biologi tanah merupakan indikator dalam menganalisis kesehatan tanah (Simarmata et al., 2019).

Pada umumnya analisis kesehatan tanah sawah dilakukan di laboratorium tanah menggunakan perlatan yang canggih dan sulit dimodifikasi oleh petani. Namun demikian, upaya-upaya pendekatan anlisis kesehatan tanah sawah secara sederhana bisa diajarkan kepada petani agar petani faham cara menilai kesehatan tanah sawahnya. Dalam rangka kegiatan Climateresilient Investigation and Innovation Project (CRAIIP), Jaringan Masyarakat Tani Indonesia (JAMTANI) bekerja sama dengan Fakultas Pertanian, Universitas Padjadjaran melakukan pelatihan analisis sederhana kesehatan tanah sawah dengan pendekatan sekolah lapang petani. Tujuan dari pelatihan ini adalah Melatih petani agar mampu secara mandiri untuk menganalisa kondisi kesehatan tanah sawah secara sederhana dan mampu memberikan rekomendasi perlakuan yang akurat untuk menyehatkan kembali tanah sawah yang sakit sesuai dengan gejala yang timbul.

Metode sekolah lapangan petani (SLP) merupakan kunci dalam peningkatan kompetensi petani dengan mempertimbangkan aspek kearifan lokal. Pelaksanaan SLP bertujuan membangun kesadaran petani untuk mau dan mampu melakukan sesuatu yang bersifat evolutif (Ernawati et al., 2015). Efektifitas pelatihan analisis sederhana kesehatan tanah sawah kepada petani melalui metode sekolah lapang perlu diuji untuk mengetahui seberapa efektif metode sekolah lapang dalam meningkatkan kemampuan petani.

\section{Bahan Dan Metode}

Penelitian dilaksanakan terhadap 17 petani yang berasal dari Desa Paledah dan Desa Ciganjeng yang terletak di Kecamatan Padaherang, Kabupaten Pangandaran, Provinsi Jawa Barat serta dari Desa Rawaapu dan Desa Cimurutu yang terletak di Kecamatan Patimuan Kabupaten Cilacap, Provinsi Jawa Tengah sebagai peserta pelatihan analisis sederhana kesehatan tanah sawah yang dilaksanakan pada tanggal 29 Februari 2020. Pelatihan ini merupakan bagian dari Climate-resilient Investigation and Innovation Project (CRAIIP) yang dilaksanakan oleh Jaringan Masyarakat Tani Indonesia (JAMTANI) dan didanai oleh Organisasi Non-Pemerintah Jerman Bread for the World (fase kedua: 2019-2022). Pemilihan peserta pelatihan dilakukan secara sengaja (Purposive Sampling) terhadap petani yang memiliki kriteria: 1) bisa membaca dan menulis, 2) pernah mengikuti pelatihan pertanian, dan 3) memiliki sawah sendiri.

Penelitian dilakukan dengan cara mengukur pengetahuan petani peserta sebelum dan sesudah mengikuti pelatihan. Pelatihan dilakukan melalui metode Sekolah Lapang Petani (SLP) dengan pendekatan pembelajaran langsung, diskusi, serta praktek di lapangan. Alat ukur yang dipergunakan dalam penelitian ini adalah kuisioner pretest dan post test. Pretest dilakukan sebelum pelatihan, sedangkan postest dilakukan setelah pelatihan. Soal yang diberikan pada saat pretest dan postest tidak berbeda. Pertanyaan yang diberikan menyangkut tentang dasar-dasar pengetahuan tentang tanah sawah dan ciri-ciri tanah sawah yang sehat. Analisis yang digunakan adalah analisis statistik non parametrik Chi-Square untuk menguji hipotesis:

H0: Tidak terdapat perbedaan keilmuan petani sesudah kegiatan penelitian

H1: Terdapat perbedaan keilmuan petani sesudah kegiatan penelitian 
Menurut Syani (1995), Chi-Square dihitung dengan rumus:

$$
\chi^{2}=\sum \frac{\left(f_{0}-f_{h}\right)^{2}}{f_{h}}
$$

di mana :

$\chi^{2}=$ nilai Chi-Square

$\mathrm{f} 0=$ frekuensi hasil observasi

$\mathrm{fh}=$ frekuensi harapan

Kriteria pengujian: Jika $\chi 2$ hitung $\leq \chi 2$ tabel maka H0 diterima

Besar kecilnya peningkatan kapasitas petani berdasarkan nilai pretest dan posttest dianalisis menggunakan uji n-gain. Rumus uji n-gain yang dikemukakan oleh Hake (1998) adalah sebagai berikut:

$g=\frac{S_{\text {post }}-S_{\text {pre }}}{100-S_{\text {pre }}}$

dimana:

$g \quad=$ nilai gain faktor

$S_{\text {post }} \quad=$ skor rata-rata nilai posttest

$S_{\text {pre }} \quad=$ skor rata-rata nilai pretest

Faktor g selanjutnya diklasifikasikan terhadap katagori: $g \geq 0,7=$ tinggi, $0,3 \leq g<0,7=$ sedang, dan $g<0,3=$ rendah.

Respons petani terhadap pelatihan yang telah dilakukan ditinjau melalui pendekatan deskriptif melalui kuesioner. Kuesioner yang diberikan berisi pertanyaan untuk mengetahui persepsi petani tehadap kegiatan, manfaat yang diperoleh, dan rencana tindak lanjut setelah kegiatan pelatihan. Pengisian kuesioner juga bertujuan untuk mengevaluasi kegiatan pelatihanpatif yang telah dilakukan. Menurut Lestari dan Mardiyanto (2017) evaluasi perlu dilakukan untuk mengetahui kelemahan dan kelebihan dari kegiatan sekolah lapangan yang telah dilakukan.

\section{Hasil dan Pembahasan}

\section{Karakteristik Petani}

Responden dalam penelitian ini adalah peserta pelatihan yaitu petani padi yang berasal dari Desa Ciganjeng, Desa Paledah, Desa Cimurutu, dan Desa Rawaapu. Peserta pelatihan terdiri dari laki-laki dan perempuan. Peserta laki-laki berjumlah sepuluh orang atau sekitar 59\% dari total peserta, sedangkan peserta perempuan berjumlah tujuh orang atau sekitar $41 \%$ dari total peserta (Gambar 1). Hampir seluruh peserta pelatihan tergolong kedalam usia produktif berdasarkan kriteria dari Badan Pusat Statistik (2020), yang menyebutkan bahwa usia produktif adalah mereka yang berusia antara 20-60 tahun. Usia sangat terkait dengan tingkat produktivitas tenaga kerja dalam usaha tani. Sebagaimana diketahui bahwa hampir seluruh aktivitas usaha tani berhubungan dengan kemampuan fisik. Petani dalam usia produktif tentu akan memiliki tingkat produktivitas yang lebih tinggi dibandingkan petani yang telah memasuki usia senja. Selain itu, petani dalam usia produktif sangat menguntungkan bagi pelaksanaan pelatihan, karena pada usia produktif petani akan cenderung lebih aktif dan memiliki keingintahuan yang besar (Noer, 2013).

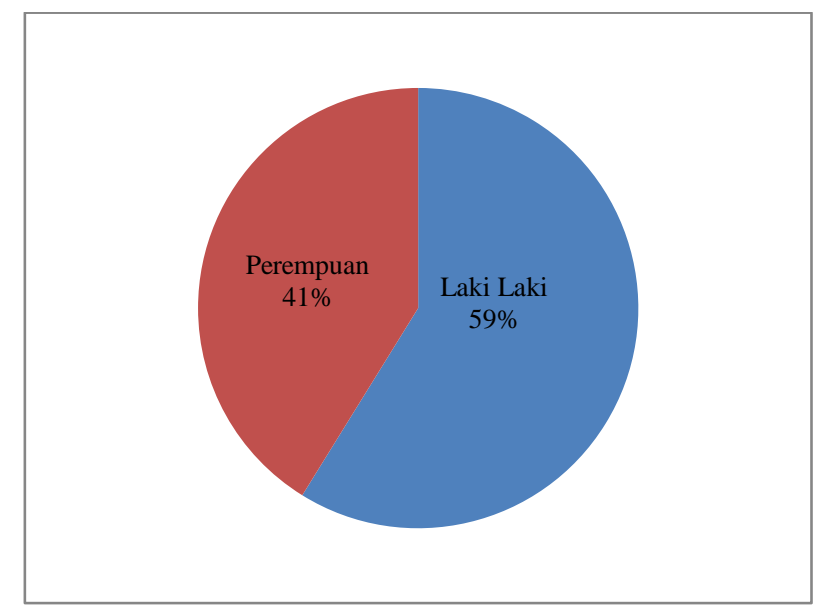

Gambar 1. Sebaran Gender Peserta Pelatihan

Peserta pelatihan dengan rentang usia 41-50 tahun menjadi yang paling banyak sekitar $41 \%$ atau tujuh orang. Sementara itu peserta dengan rentang usia diatas 60 tahun menjadi yang paling sedikit yaitu hanya satu orang (Gambar 2). Sebagian besar petani di Indonesia memiliki usia lebih dari 40 tahun dan hal tersebut diakibatkan oleh sulitnya regenerasi petani (BPS, 2020). Sulitnya regenerasi petani tak hanya terjadi di Indonesia, namun ketertarikan kaum muda terhadap pertanian sangat rendah di negara-negara berkembang lainnya (Dayat et al., 2020). Sulitnya proses regenerasi petani menjadi suatu permasalahan yang harus segera dicarikan solusinya untuk mempertahankan keberlanjutan pertanian di Indonesia.

Permasalahan lain yang terjadi dibidang pertanian adalah rendahnya tingkat pendidikan petani. Rendahnya tingkat pendidikan petani di Indonesia diduga menjadi penyebab sulitnya proses transfer teknologi kepada petani (Seran et al., 2011). Berdasarkan sebaran tingkat pendidikan sebagaian besar peserta telah mengeyam pendidikan sampai tingkat Sekolah Menengah Pertama (SMP). Pada Gambar 3 terlihat bahwa peserta dengan tingkat pendidikan Sekolah Dasar (SD) berjumlah empat orang (23\%), SMP sepuluh orang (59\%), dan Sekolah Menengah Atas (SMA) berjumlah tiga orang (18\%). Tingkat pendidikan berpengaruh terhadap kemampuan petani dalam memahami dan menerima informasi. 
Selain itu tingkat pendidikan juga dapat berpengaruh dalam proses pengambilan keputusan (Dayat et al., 2020). Oleh karena itu, petani dengan tingkat pendidikan yang lebih tinggi diharapkan memiliki kemampuan yang lebih baik dan dapat membantu petani lain yang memiliki tingkat pendidikan lebih rendah agar proses pelatihan berjalan dengan kondusif.

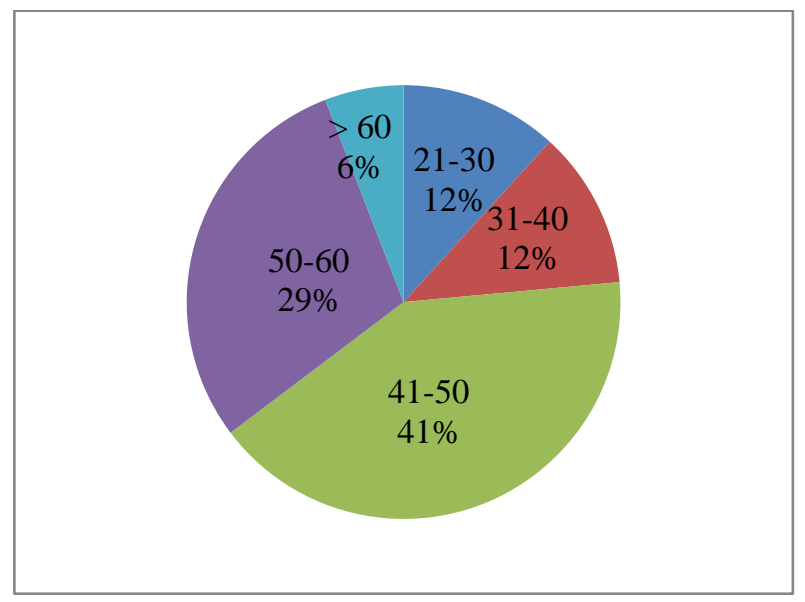

Gambar 2. Sebaran Usia Peserta Pelatihan

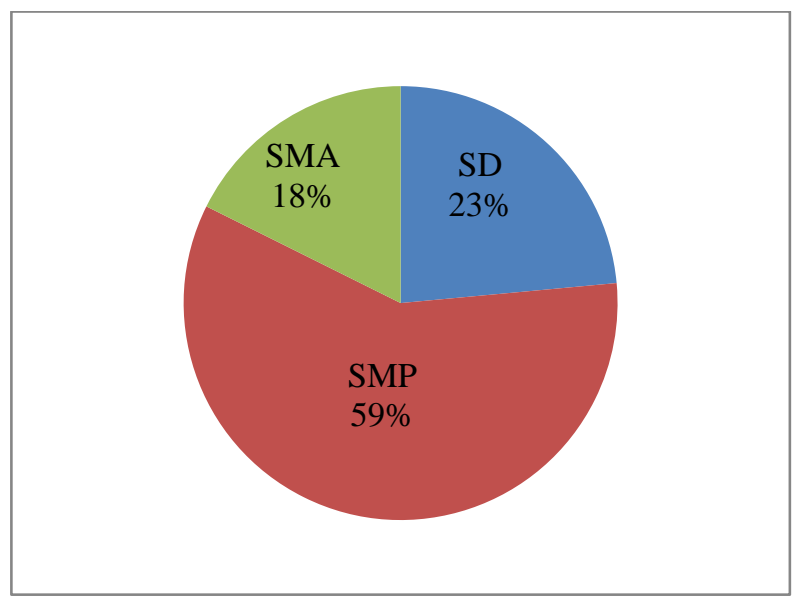

Gambar 3. Sebaran Tingkat Pendidikan Peserta Pelatihan

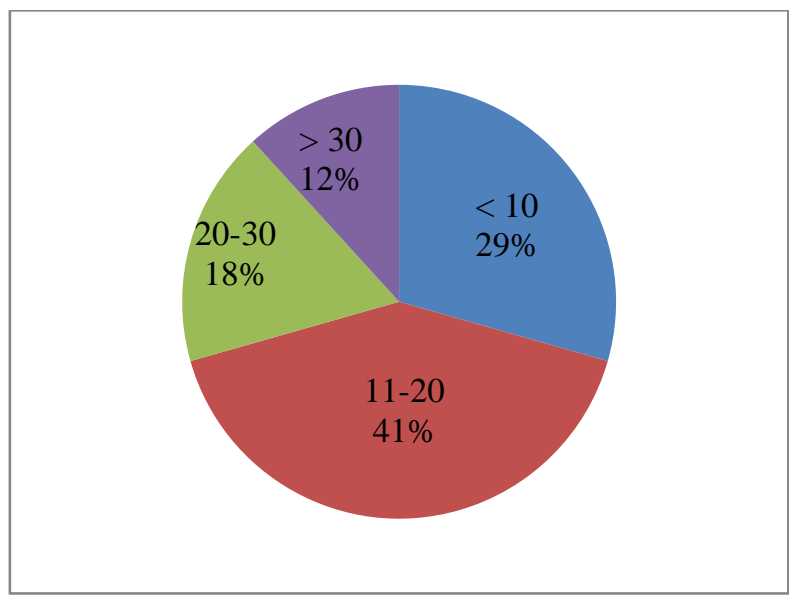

Gambar 4. Sebaran Pengalaman Lama Bertani Padi Peserta Pelatihan

Hal lain yang berpengrauh terhadap penerimaan materi selama pelatihan adalah pengalaman bertani (Ernawati et al. 2015). Sebanyak lima peserta (29\%) memiliki pengalaman bertani kurang dari 10 tahun, sebanyak tujuh peserta $(41 \%)$ memiliki pengalaman bertani 11-20 tahun, sebanyak tiga peserta (18\%) memiliki pengalaman bertani 20-30 tahun, dan sebanyak dua peserta (12\%) memiliki pengalaman bertani lebih dari 30 tahun (Gambar 4). Menurut Noer (2013) petani dengan pengalaman usaha tani lebih dari 10 tahun tergolong petani yang berpengalaman.

Pengalaman adalah guru yang nyata, pengalaman tidak selalu lewat proses belajar formal, tetapi juga melalui rangkaian peristiwa yang pernah dihadapi. Semakin lama pengalaman petani, maka semakin banyak peristiwa dan persoalan yang pernah dihadapi, sehingga mampu mengambil keputusan yang efektif dalam mengelola sarana produksi dan lebih terampil dalam mengembangkan usaha tanin dan meningkatkan produksinya (Harahap et al., 2018). Petani yang berpengalaman dapat mendukung keberhasilan proses pelatihan melalui metode sekolah lapangan petani karena petani tersebut telah mengalami banyak kejadian ataupun persoalan berkaitan dengan usaha taninya. Sehingga petani tersebut akan lebih aktif dalam bertanya ataupun memberikan pendapat selama pelatihan (Ernawati et al. 2015).

\section{Peningkatan Keilmuan Petani}

Sumber daya manusia berhubungan dengan keilmuan, dimana keilmuan dapat diperolerh dari proses pembelajaran. Peningkatan keilmuan petani sangat penting guna mendukung perubahan perilaku petani (Lestari dan Mardiyanto, 2017). Peningkatan 
keilmuan petani peserta penelitian partisipatif diukur dengan cara membandingkan hasil pretest dan postest. Hasil pretest peserta pelatihan berkisar antara 30-70 (skala 10-100), sedangkan hasl postest berkisar antara 50-100 (Gambar 5). Secara umum terjadi peningkatan hasil postest dibandingkan dengan pretest. Rata-rata nilai pretest peserta pelatihan mencapai 54,12, sedangkan nilai rata-rata postest mencapai 65,88. Dengan demikian terdapat peningkatan nilai rata-rata sebesar $21,74 \%$.
Perbedaan nilai postest dengan nilai pretest dianalisis berdasarkan uji $\mathrm{T}$ menggunakan aplikasi SPSS 17. Hasil uji T dengan $\mathrm{n}=17$, taraf kesalahan 5\% menunjukkan nilai $t_{\text {hitung }}$ sebesar $-4,51$. Nilai $t_{\text {hitung }}$ pada uji $\mathrm{T}$ merupakan nilai mutlak sehingga nilainya menjadi 4,51 dan lebih tinggi di banding nilai $t_{\text {tabel }}$ yang mencapai 2,12. Hal tersebut menunjukkan bahwa pelatihan yang dilaksanakan berpengaruh signifikan dalam meningkatkan keilmuan peserta pelatihan.

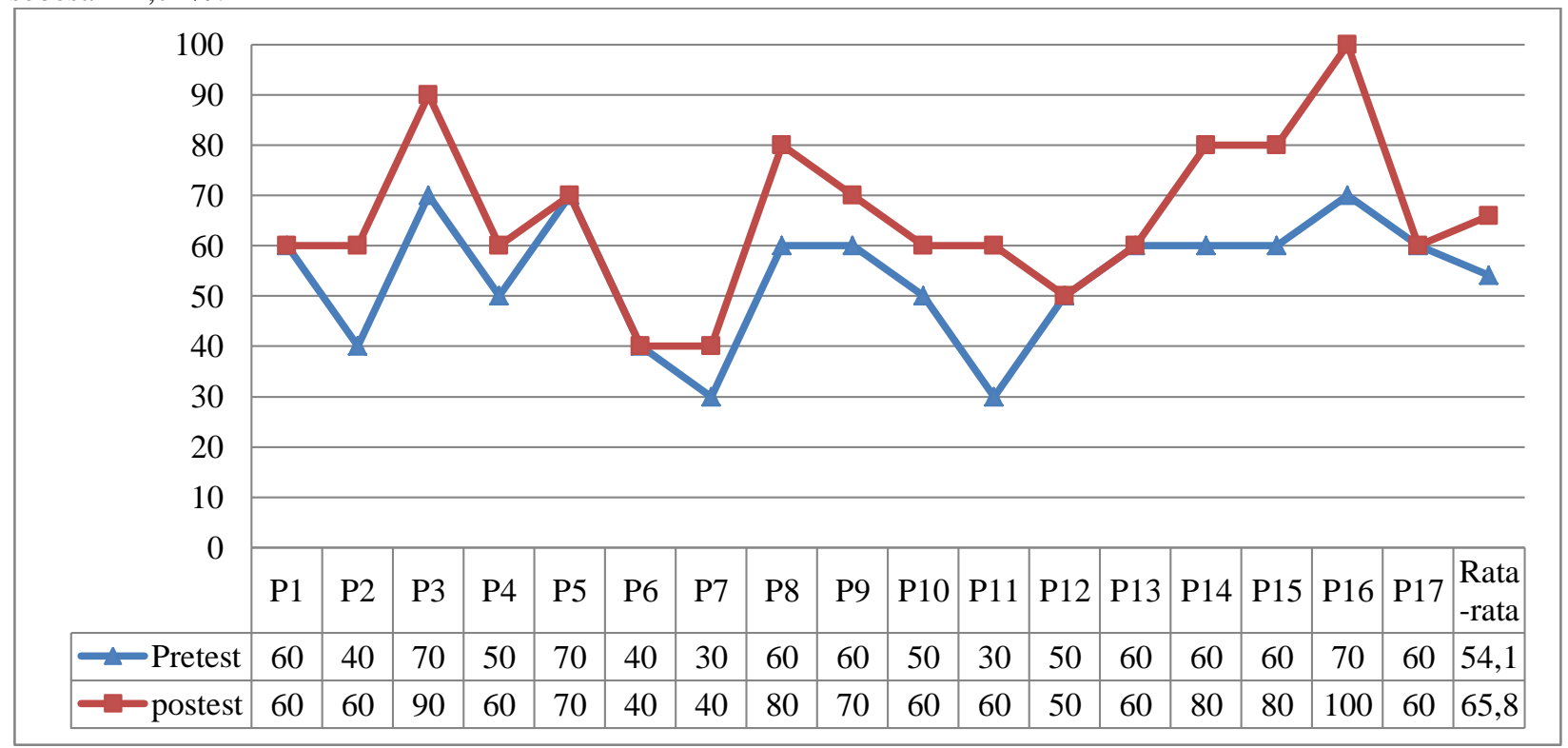

Gambar 5. Nilai Pretest dan Postest Petani Peserta Pelatihan

Besar kecilnya peningkatan nilai postest terhadap pretest diuji menggunkan gain faktor berdasarkan kriteria rendah, sedang dan tinggi. Menurut Hake (1998) apabila nilai gain faktor (g) kurang dari 0,3 berarti peningkatan tergolong rendah, kemudian apabila nilai g berkisar antara 0,3-0,7 menunjukkan peningkatan yang tergolong sedang, dan apabila nilai $\mathrm{g}$ lebih dari 0,7 maka peningkatan tergolong tinggi. Berdasarkan uji gain faktor nilai $\mathrm{g}$ mencapai 0,26 sehingga peningkatan keilmuan petani pada pelatihan analisis kesehatan tanah sawah berdasarkan hasil preetest dan postest tergolong rendah. Peningkatan keilmuan petani setelah mengikuti serangkaian program pelatihan dipengaruhi oleh dua faktor utama yaitu faktor internal dan faktor eksternal. Faktor internal yaitu faktor yang berasal dari petani yang terlibat seperti usia, tingkat pendidikan, dan pengalaman bertani, sedangkan faktor eksternal meliputi penyampaian materi dari narasumber, ketersediaan sarana dan prasarana yang menunjang, dan tingkat kondusif saat kegiatan dilakukan (Mardiyanto dan Prastuti 2016).

Tabel 1. Peningkatan Nilai Pretest dan Postest Petani Peserta Pelatihan

\begin{tabular}{cccccccc}
\hline \multicolumn{2}{c}{ Nilai } & \multirow{2}{*}{\begin{tabular}{c} 
Kenaikan \\
\cline { 5 - 8 } \cline { 5 - 8 } Pretest
\end{tabular}} & Posttest & & \multicolumn{2}{c}{ Uji t } & \multicolumn{2}{c}{ Faktor gain } \\
\hline 54,12 & $65,88^{*}$ & 21,74 & 16 & $-4,51$ & 2,12 & 0,26 & Rendah \\
\hline
\end{tabular}

Keterangan: $*=$ Terdapat peningkatan yang signifikan pada $\mathrm{P}<0.05$ berdasarkan uji $\mathrm{T}$

Rendahnya peningkatan nilai postest terhadap pretest berdasarkan nilai $\mathrm{g}$ diduga karena petani yang menjadi peserta pelatihan telah memiliki keilmuan yang cukup baik sebelum mengikuti pelatihan. Hal 
tersebut terlihat dimana sebagain besar peserta memiliki nilai pretest 50 ke atas dan hanya empat peserta yang memiliki nilai di bawah 50 . Hal tersebut mengakibatkan rata-rata nilai pretest mencapai 54,12. Pada sub bab sebelumnya dijelaskan bahwa sebagain besar petani peserta pelatihan memiliki tingkat pendidikan sampai jenjang SMP. Hasil penelitian Prayoga (2020) pada kegiatan sekolah lapang, petani dengan tingkat pendidikan relatif tinggi memiliki nilai preetest yang tinggi pula sehingga peningkatan pada nilai postest rendah. Selain itu berdasarkan lamanya bertani hampir semua peserta adalah petani berpengalaman dengan pengalaman bertani padi lebih dari 10 tahun, hanya lima peserta yang memiliki pengalaman kurang dari 10 tahun. Hal tersebut juga diduga berpengaruh terhadap rendahnya niali g karena menurut Harahap et al. (2018) dengan pengalaman bertani yang cukup lama maka keilmuan petani akan semakin bertambah.

Rendahnya nilai g juga diakibatkan terdapat lima peserta yang tidak mengalami peningkatan nilai postest. Hal tersebut diduga akibat keterbatasan kemampuan menyerap informasi yang diberikan. Selain itu juga kecakapan pemateri juga menjadi faktor untama dalam tersampaikannya materi secara baik kepada peserta pelatihan. Untuk mengetahui efektivitas pelatihan selain berdasarkan dari nilai pretest dan postest peserta pun memberikan penilaian melalui kuisioner berdasarkan persepsi mereka terhadap pelaksanaan pletahian yang dilakukan.

\section{Respon Petani}

Persepsi petani terhadap pelaksanaan pelatihan sangat penting sebagai bahan evaluasi untuk perbaikan di masa mendatang (Prayoga, 2020). Semua peserta memberikan penilaian terhadap materi, sarana dan prasarana, kondusivitas pelatihan, dan kemungkinan adopsi teknologi oleh peserta. Berdasarkan hasil dari kuesioner secara umum kegiatan pelatihan yang dilakukan berjalan dengan baik. Pada Tabel 2 terlihat bahwa petani setuju dan sangat setuju bahwasannya materi yang diberikan sesuai dengan kebutuhan petani. Selain itu sebanyak delapan petani peserta pelatihan menunjukkan sikap setuju dan sisanya sebanyak sembilan peserta menunjukkan sikap sangat setuju bahwa pemateri menyampaikan materinya dengan baik. Kompetensi narasumber merupakan faktor yang signifikan berkontribusi terhadap keberhasilan pelatihan atau pembelajaran (Haslinda et al., 2009). Oleh karena itu, kriteria utama yang dibutuhkan oleh seorang narasumber atau instruktur adalah: (i) menguasai materi yang diajarkan; (ii) terampil mengajar secara sistematik, efektif, dan efisien; serta (iii) mampu menggunakan metode dan media yang relevan (Mardiyanto \& Prastuti, 2016).

Tabel 2. Persepsi Petani Terhadap Kegiatan Pelatihan

\begin{tabular}{clccc}
\hline \multirow{2}{*}{ No } & \multicolumn{1}{c}{ Kriteria } & \multicolumn{3}{c}{ Persepsi } \\
\cline { 3 - 5 } & & $\begin{array}{c}\text { Tidak } \\
\text { Setuju }\end{array}$ & Setuju & $\begin{array}{c}\text { Sangat } \\
\text { Setuju }\end{array}$ \\
\hline 1 & Materi sesuai dengan kebutuhan petani & 0 & 10 & 7 \\
2 & Pemateri meyampaikan materi dengan baik & 0 & 8 & 9 \\
3 & Materi yang disampaikan mudah diterapkan & 0 & 7 & 10 \\
4 & Ketersediaan sarana dan prasarana sangat menunjang kegiatan & 0 & 11 & 6 \\
5 & Pelatihan berlangsung kondusif & 0 & 9 & 8 \\
6 & Pelatihan yang diberikan bermanfaat untuk petani & 0 & 5 & 12 \\
7 & Materi pelatihan akan coba diaplikasikan secara mandiri & 0 & 4 & 13 \\
\hline
\end{tabular}

Materi yang diberikan pada saat pelatihan analisis sederhana kesehatan tanah sawah dinilai mudah diterapkan oleh petani. Selain itu ketersediaan sarana dan prasarana pun sangat menunjang kegiatan pelatihan. Pelatihan yang dilaksanakan dinilai petani berlangsung dengan kondusif sebanyak sembilan peserta memeberikan sikap setuju dan sebanyak delapan peserta memberikan sikap sangat setuju (Tabel 2). Pelatihan yang diberikan dinilai memberikan manfaat kepada petani. Manfaat yang diharapkan setelah pelatihan ini adalah petani mampu melakukan analisis kesehatan terhadap tanah sawah yang dimiliki, sehingga petani bisa melakukan upaya-upaya agar tanah sawahnya memberikan performa yang optimal. Berdasarkan hasil kuisioner sebanyak empat peserta memberikan sikap setuju dan sebanyak 13 peserta memberikan sikap sangat setuju untuk mencoba mengaplikasikan secara mandiri materi pelatihan analisis sederhana kesehatan tanah sawah di lahannya masing-masing. 
Adopsi teknologi dapat diartikan sebagai proses perubahan perilaku baik yang berupa pengetahuan (cognitive), sikap (affective), maupun keterampilan (psychomotoric) pada diri seseorang setelah menerima informasi teknologi. Penerimaan di sini mengandung arti tidak sekedar "tahu" tetapi sampai benar-benar dapat melaksanakan atau menerapkannya dengan benar serta menghayatinya dalam kehidupan dan usaha taninya (Mardikanto, 2010). Rogers (1983), menjelaskan bahwa secara konseptual, sebelum masyarakat mau menerima/menerapkan dengan keyakinan sendiri, proses adopsi melalui beberapa tahapan adalah (i). Awareness atau kesadaran, yaitu penerima manfaat mulai sadar tentang inovasi yang ditawarkan oleh fasilitator; (ii). Interest atau tumbuhnya minat yang seringkali ditandai oleh keinginannya untuk bertanya atau mengetahui lebih banyak tentang inovasi yang ditawarkan fasilitator; (iii). Evaluation atau penilaian terhadap baik/buruknya atau manfaat inovasi yang telah diketahui secara lebih lengkap; (iv). Trial atau mencoba dalam skala kecil untuk lebih menyakinkan penilaian sebelum menerapkan pada skala yang lebih luas; (v). Adoption atau menerima/menerapkan dengan penuh keyakinan berdasarkan penilaian dan uji coba yang telah dilakukan/diamatinya sendiri.

\section{Kesimpulan}

1. Berdasarkan hasil uji T terdapat perbedaan yang nyata antara nilai rata-rata postest $(65,88)$ dengan nilai rata-rata pretest $(54,12)$ dan terjadi peningkatan sebanyak $21,74 \%$. Berdasarkan nilai gain faktor, peningkatan keilmuan petani setelah mengikuti pelatihan analisis tanah sawah sederhana tergolong sedang.

2. Petani peserta pelatihan memberikan sikap yang positif terhadap kegiatan pelatihan dimana petani seluruhnya setuju dan sangat setuju bahwa materi sesuai dengan kebutuhan petani, pemateri menyampaikan materi dengan baik, materi yang diberikan mudah diterapkan, ketersediaan sarana dan prasarana sangat menunjang kegiatan, pelatihan berlangsung kondusif, pelatihan yang diberikan bermanfaat untuk petani, dan materi pelatihan akan coba diaplikasikan secara mandiri.

\section{Ucapan Terima Kasih}

Penulis mengucapkan terima kasih kepada Universitas Padjadjaran (UNPAD) yang telah mendukung dan menyediakan fasilitas laboratorium. Studi ini didanai oleh Organisasi Non-Pemerintah Jerman Bread for the World (fase kedua: 2019-2022) sebagai bagian dari Climate-resilient Investigation and Innovation Project (CRAIIP) yang dilaksanakan oleh Jaringan Masyarakat Tani Indonesia (JAMTANI). Penulis juga berterima kasih kepada petani peserta pelatihan yang telah memberikan kontribusi dalam penelitian ini.

\section{Daftar Pustaka}

BPS. (2020). Statistik Indonesia. Badan Pusat Statistik, Jakarta.

Dayat, Anwarudin, Oeng, dan Makhmudi, M. (2020). Regeneration Of Farmers Through Rural Youth Participation In Chili Agribusiness. International Journal of Scientific and Technology Research. Vol. 9 (3): 1201-1206.

Ernawati, L., Djafar, dan Sudirman. (2015). Program Sekolah Lapangan Pengelolaan Tanaman Terpadu Sebagai Upaya Peningkatan Kapasitas Petani. Jurnal Tesis PMIS-UNTAN. Vol. 1 (1): 1-21.

Hake, R R. (1998). Interactive-Engagement Vs Traditional Methods: A Six-ThousandStudent Survey of Mechanics Test Data For Introductory Physics Courses. American Journal of Physics. Vol. 66 (1): 1-3.

Harahap, J., Sriyoto, dan Yuliarti, E. (2018). Faktorfaktor Yang Mempengaruhi Pengambilan Keputusan Petani Salak Dalam Memilih Saluran Pemasaran. AGRISEP. Vol. 17 (1): 95-106.

Haslinda A. \& Mahyuddin, M.Y. (2009). The Effectiveness of Training in The Public Service. American Journal of Scientific Research. Vol. 10 (6): 39 - 51.

Kusrachdiyanti, N. M., Khumairah, F. H., Hindersah, R., and Simarmata, T. (2020). Isolatic Rhizobactery and Isolative Nitrogen Testing as Growth Extractor at Saline Soils Ecosystems. Jurnal Ilmiah Pertanian. Vol. 16 (2): 116125.

Lestari, Fitri dan Mardiyanto, T. Cahyo. (2017). Upaya Peningkatan Kapasitas Petani Terhadap Teknologi Pembibitan Cabai Sehat Melalui Pelatihan Di Kabupaten Boyolali. Buletin 
Pengkajian Teknologi Pertanian. Vol. 12 (1): 465-473.

Mardikanto, T. (2010). Komunikasi Pembangunan. Program Studi Pemberdayaan Masyarakat. Program Pascasarjana UNS. Surakarta.

Mardiyanto, T. C. \& Prastuti, T. R. (2016). Efektivitas Pelatihan Teknologi Budidaya Bawang Putih Varietas Lokal Ramah Lingkungan dengan Metode Ceramah di Kabupaten Karanganyar. Jurnal Agraris. Vol. 2 (1): 61-68.

Nafisah, N., Hairmansis, A., and Sitaresmi, T. (2017). Grain Yield of Rice Elite Lines Under Saline Prone Condition in Cilamaya Wetan, Karawang Subdistrict West Java. Journal of Suboptimal Lands. Vol. 6 (1): 21-32.

Noer, Hasmari. (2013). Prospek Pengembangan Tanaman Pangan Pada Lahan Kering Ditinjau dari Keputusan Petani dalam Menerapkan Teknologi Usahatani (Suatu kasus pada Petani Tanaman Pangan Lahan Kering di Kabupaten Morowali Provinsi Sulawesi Tengah) [Disertasi]. Universitas Padjadjaran, Bandung.

Prayoga, M. Khais. (2020). Riset Aksi Partisipatif Dalam Pemilihan Varietas Padi Dan Amelioran Untuk Meningkatan Kapasistas Adaptasi Petani Terhadap Cekaman Genangan Dan Salinitas [Disertasi]. Universitas Padjadjaran, Bandung.

Rogers, E. M. and F. F. Shoemaker. (1983). Diffusion of Innovation. Free Press, New York

Rostini, Neni, M. Khais Prayoga, T. Simarmata, Mieke R. Setiawati, S. Stoeber, and K. Adinata. 2020. Selection of Five Rice Varieties (Oryza sativa) under Salinity Stress in Climate Field Schools. In Leal Filho, W., Nagy G., Borga M., Chávez Muñoz D., Magnuszewsk A. (Eds) Climate Change, Hazards and Adaptation Options: handling the impacts of a changing climate. Pp. 799-811. New York: Springer, Cham.

Seran, Y. L., Kote, M. dan Triastono, J. (2011). Peningkatan Kapasitas Petani Jagung Melalui Uji Coba Teknologi Bersama Petani Dalam Mendukung Penguatan Penyuluhan Pertanian. Proshiding Seminar Nasional Serealia thn. 2013, hlm. 675-683.

Setiwati, M. R., Prayoga, M. K., Stoeber, S., Adinata, K., Simarmata, T. (2020). Performance of rice paddy varieties under various organic soil fertility strategies. Open Agriculture. Vol. 5 (1): 509-515

Simarmata T., Setiawati, M. R, Herdiantoro, D. and Fitriatin, B. N. (2018). Managing of OrganicBiofertilizers Nutrient Based and Water Saving Technology for Restoring the Soil Health and Enhancing the Sustainability of Rice Production in Indonesia. IOP Conf. Series: Earth and Environmental Science. 205 (2018) 012051

Simarmata, T., Setiawati, M. R., dan Herdiyantoro, D. (2019). Evaluasi Cepat Kesehatan Tanah Lahan Kering di Lapangan. Unpad Press, Bandung.

Suprayogi, P., \& Salsabila, J. (2019). Growth Response and Yield of Saline Tolerant Rice Varieties to Bio-fertilizer Application at Central Java North Coastal Saline Paddy Field. IOP Conference Series: Earth and Environmental Science, $\quad 406(1), \quad 1-5$. https://doi.org/10.1088/17551315/406/1/012001

Syani, Abdul. (1995). Pengantar Metode Statistik Nonparametrik. Pustaka, Jakarta. 